\title{
No evidence of real progress in treatment of acute pain, | 993-2012: scientometric analysis
}

This article was published in the following Dove Press journal:

Journal of Pain Research

I I April 2014

Number of times this article has been viewed

\section{Darin J Correll \\ Kamen V Vlassakov \\ Igor Kissin}

Department of Anesthesiology, Perioperative and Pain Medicine, Brigham and Women's Hospital, Harvard Medical School, Boston, MA, USA
Correspondence: Igor Kissin

Department of Anesthesiology, Brigham and Women's Hospital, 75 Francis Street, Boston, MA 02II5, USA

$\mathrm{Tel}+\mathrm{l} 6177325052$

Fax + I 6177340682

Email kissin@zeus.bwh.harvard.edu
Abstract: Over the past 2 decades, many new techniques and drugs for the treatment of acute pain have achieved widespread use. The main aim of this study was to assess the progress in their implementation using scientometric analysis. The following scientometric indices were used: 1) popularity index, representing the share of articles on a specific technique (or a drug) relative to all articles in the field of acute pain; 2) index of change, representing the degree of growth in publications on a topic compared to the previous period; and 3) index of expectations, representing the ratio of the number of articles on a topic in the top 20 journals relative to the number of articles in all $(>5,000)$ biomedical journals covered by PubMed. Publications on specific topics (ten techniques and 21 drugs) were assessed during four time periods (1993-1997, 1998-2002, 2003-2007, and 2008-2012). In addition, to determine whether the status of routine acute pain management has improved over the past 20 years, we analyzed surveys designed to be representative of the national population that reflected direct responses of patients reporting pain scores. By the 2008-2012 period, popularity index had reached a substantial level ( $\geq 5 \%)$ only with techniques or drugs that were introduced 30-50 years ago or more (epidural analgesia, patient-controlled analgesia, nerve blocks, epidural analgesia for labor or delivery, bupivacaine, and acetaminophen). In 2008-2012, promising (although modest) changes of index of change and index of expectations were found only with dexamethasone. Six national surveys conducted for the past 20 years demonstrated an unacceptably high percentage of patients experiencing moderate or severe pain with not even a trend toward outcome improvement. Thus, techniques or drugs that were introduced and achieved widespread use for acute pain management within the past 20 years have produced no changes in scientometric indices that would indicate real progress and have failed to improve national outcomes for relief of acute pain. Two possible reasons for this are discussed: 1) the difference between the effectiveness of old and new techniques is not clinically meaningful; and 2) resources necessary for appropriate use of new techniques in routine pain management are not adequate.

Keywords: continuous nerve block, epidural analgesia, multimodal analgesia, nerve block, pain management, patient-controlled intravenous analgesia, patient-controlled epidural analgesia, postoperative pain

\section{Introduction}

In 1992, the Agency for Health Care Policy and Research (AHCPR), US Department of Health and Human Services, issued the Acute Pain Management Operative or Medical Procedures and Trauma guidelines. ${ }^{1,2}$ These guidelines recognize the widespread inadequacy of pain management and set goals for reduction of the incidence and severity of patients' acute postoperative or posttraumatic pain. One year later, the first national patient-based survey providing reliable information on acute pain management in US 
hospitals confirmed the poor status of acute pain management: $77 \%$ of adults reported pain after surgery, with $80 \%$ of these experiencing moderate to extreme pain. ${ }^{3}$ Another national patient-based survey conducted in 1992-1993 in English hospitals demonstrated similar inadequacy in acute pain management. Of the $61 \%$ of hospital patients who suffered pain, $87 \%$ had moderate or severe pain. ${ }^{4}$

During the past 2 decades, new technologies for improvement of acute pain management have achieved widespread use: patient-controlled analgesia has gained popularity; postoperative epidural analgesia has become commonplace; there has been a wide increase in the use of continuous peripheral nerve blocks; and acute pain nurse-based services have been designed. ${ }^{5-8}$ In addition, new pharmacological agents have been developed and used for the treatment of pain..$^{8,9}$ The main aim of this study was to assess the progress in the development of new techniques and drugs for the treatment of acute pain over the past 20 years with the use of scientometric analysis. We also sought to answer the following question: have new developments changed the status of acute pain management since the issuance of the AHCPR guidelines?

\section{Methods}

To assess the development of new techniques and drugs for the treatment of acute pain, we used the following three publication parameters as signs of success in pain research. 1) Popularity index (PI) is the share of articles on a specific technique (or a drug) relative to all articles in the field of acute pain ("acute pain" OR "postoperative pain"). A specific threshold of $1 \%$ (arbitrary) was chosen to select topics on which the number of publications (2008-2012) reached a substantial level. 2) Index of change (IC) represents the change in number of publications during a 5-year period on a technique (or a drug) compared to that in the previous 5 years (immediately prior to the time period). It reflects the change in interest for a topic in general. A specific threshold for this index was the growth beyond the increase in number of publications in the whole field of acute pain during the same time interval. 3) Index of expectations (IE), or Top Journal Selectivity Index (TJSI), ${ }^{10-14}$ represents the ratio of the number of all types of articles on a particular topic in the top 20 journals relative to number of articles in all $(>5,000)$ biomedical journals covered by PubMed over 5 years. It reflects the predominance of interest in a topic in the top journals. A TJSI value $\geq 10$ was selected to represent high expectations of success.

Specific topics with PI 1\% or higher (in 2008-2012) were selected for assessment using the IC and IE during four time periods: 1993-1997, 1998-2002, 2003-2007, and 2008-2012. The articles were collected mainly using the National Library of Medicine's PubMed website (http:// www.ncbi.nlm.nih.gov/pubmed/). Only articles published in English were included. Search terms related to the techniques or drugs used for the treatment of acute pain were taken from various articles ${ }^{5-9,13,14}$ and textbooks. ${ }^{15-17}$ The following techniques were included: acute pain service; continuous epidural anesthesia; continuous nerve block; epidural analgesia (all types); epidural analgesia for labor or delivery; multimodal analgesia; nerve blocks (all types); patient-controlled intravenous analgesia (PCA); patient-controlled epidural analgesia (PCEA); patient-controlled nerve block; preemptive analgesia; and wound infiltration. The following drugs were searched: acetaminophen; aspirin; bupivacaine; celecoxib; clonidine; dexamethasone; dexmedetomidine; diclofenac; fentanyl; gabapentin; hydrocodone; hydromorphone; ibuprofen; ketorolac; levobupivacaine; methadone; oxycodone; pregabalin; remifentanil; ropivacaine; and tramadol.

A technique or drug term was entered in the search box with the following keyword combination: AND ("acute pain" OR "postoperative pain"). If the name of a technique included the word "analgesia", the above combination was not added. To create separate categories of epidural analgesia (such as epidural analgesia for labor or delivery), the following additional terms were placed in the search box: AND (labor OR delivery). To separate articles on peripheral nerve blocks from those related to spinal or epidural blocks, the following addition was placed in the search box: NOT (spinal OR epidural). To eliminate articles on opioids used only as adjuncts to anesthesia, the following terms were added in the search box: NOT "general anesthesia”. Filters for languages (English) and publication dates (custom range) were used. All types of articles were taken into account.

To determine IE (TJSI), ${ }^{10-12}$ the 20 top journals were selected based on two factors: 1) their rank sorted by the impact factor, as indicated by Journal Citation Reports for 2012; and 2) the journal specialty area. The journals included anesthesiology, pain, neurology, and surgery journals (ten journals) and general biomedical journals (also ten): American Journal of Surgery; Anesthesiology; Annals of Internal Medicine; Annals of Neurology; Annual Review of Pharmacology and Toxicology; Annals of Surgery; Archives of Surgery; British Journal of Anaesthesia; Journal of the American Academy of Orthopedic Surgery; Journal of Clinical Investigation; JAMA; Lancet; Lancet Neurology; New England Journal of Medicine; Nature Medicine; Nature Reviews Drug Discovery; Pain; 
Pharmacological Reviews; Surgery; and Trends in Pharmacological Sciences.

To assess whether routine acute pain management has improved over the past 20 years, the following survey search was performed. We analyzed only surveys designed to be representative of the national population that reflected direct responses of patients reporting pain scores (or pain relief scores). Articles published in English (1993-2012) were selected mainly using the National Library of Medicine's PubMed website. The following combination of search terms was used: ("acute pain" OR "postoperative pain") AND ("pain control" OR "pain relief" OR "pain treatment" OR "pain management”) AND (“pain intensity" OR "pain score") AND (survey OR audit OR evaluation). In addition to the electronic search of articles, related publications appearing in the reference lists of reports and reviews were also searched manually. The results of an initial search were reviewed to exclude the following types of articles: 1) articles representing the opinions of physicians or nurses involved in pain treatment rather than direct responses of patients; 2) surveys not reporting pain scores or pain relief scores; 3) surveys based solely on results from a single institution; and 4) surveys based on data exclusively on one type of surgery, one type of acute pain, or one modality of pain treatment. (The exclusion of specialized systems of pain management, which usually can afford additional resources for specific aims, should better reflect routine pain treatment.) Thus, surveys represent routine pain treatment of patients with multiple types of acute pain treated in the various types of institutions using multiple pain treatment modalities. These surveys reflect reports on pain intensity by indicating its numerical value.

We also performed a specific analysis of the results of studies directly comparing the pain relief effectiveness of two treatment modalities: PCA and PCEA. Only prospective, randomized studies reporting pain scores and having more than 20 patients per treatment group were collected. The differences in pain intensity scores reported in these studies on the first postoperative day were assessed from both statistical and clinical points of view. Statistically significant differences $(P<0.05)$ and clinically noticeable differences (differences $\geq 13$ on a pain scale of $0-100^{18,19}$ ) were noted for pain at rest and with activity.

\section{Results}

\section{Scientometrics}

Techniques

A scientometric assessment of techniques for the treatment of acute pain is presented in Table 1. During 2008-2012,

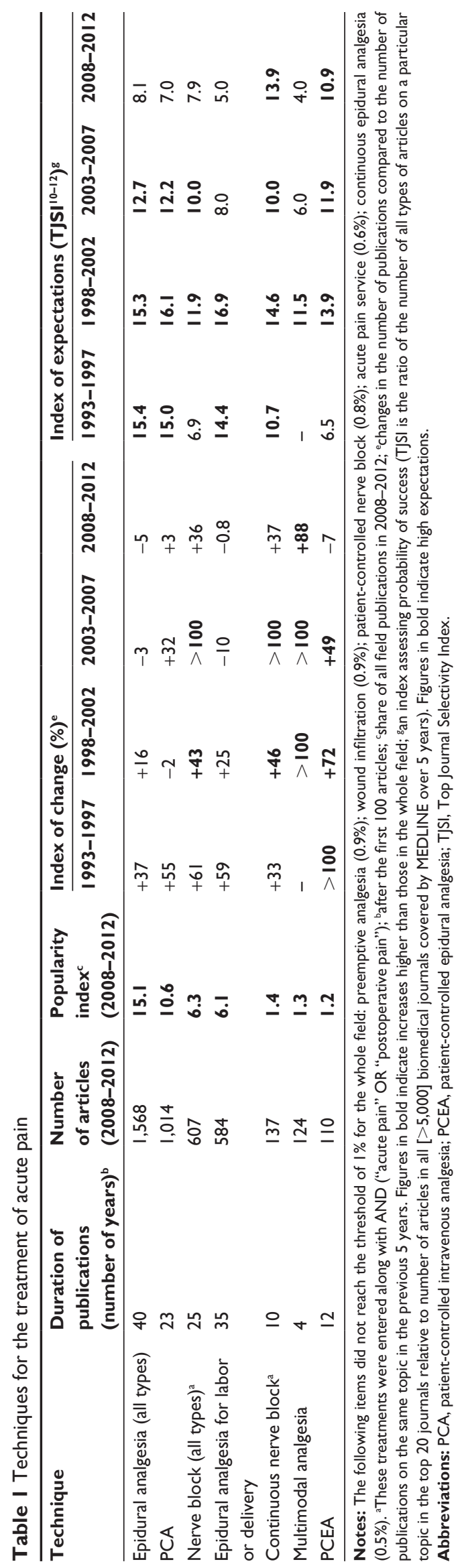


the PI was greater than 5\% for only four techniques of acute pain treatment: epidural analgesia, PCA, nerve blocks, and epidural analgesia for labor or delivery. PI did not exceed $1.5 \%$ for continuous nerve block, multimodal analgesia, or PCEA. Because the PIs for wound infiltration, preemptive analgesia, and acute pain service were all under $1 \%(0.9 \%$, $0.9 \%$, and $0.6 \%$, respectively), these terms are not included in the table.

Two relatively new treatment techniques, continuous nerve block and PCEA, demonstrated impressive increases in IC and IE over the past 20 years. However, during the last 5-year period (2008-2012), despite high IE (13.9 for continuous nerve block and 10.9 for PCEA), IC growth slowed with continuous nerve block and even declined with PCEA (Table 1). IC with multimodal analgesia has shown consistent growth since 1998; however, IE was rather low in both the 2003-2007 and 2008-2012 periods (6.0 and 4.0, respectively).

\section{Drugs}

Of 21 drugs used in acute pain management that were included in the search, the 13 with PI greater than $1 \%$ in 2008-2012 are presented in Table 2. Of those, the PI of both bupivacaine and acetaminophen was more than 5\% (7.4\% and $5.4 \%$, respectively). In 2008-2012, only dexamethasone showed impressive increases in both IC and IE (88 and 12.0, respectively). Ketamine-related IC and IE consistently increased over the entire 20-year period (1993-2012). However, in 2008-2012, those increases slowed and the increase in IC for ketamine (36) was even less than that for publications in the whole field of acute pain (42). The levobupivacainerelated increases in 2003-2007 and 2008-2012 were substantial only for IC (see Table 2).

\section{National surveys}

The initial search identified 115 articles published in the past 20 years (1993-2012), from which only 30 surveys relevant to the treatment of acute pain were selected (see Figure 1 and "Supplementary material"). In the next step, four other types of articles were excluded (as described in "Methods"), leaving only six articles that represent national surveys and reflect routine patient care (Table 3)., ${ }^{3,413,20-22}$ Each of them has several hundred to several thousand patients with multiple types of acute pain treated in various types of treatment centers using multiple pain treatment modalities. Three surveys are US national studies and the others are national surveys conducted in England, France, and Germany. All surveys reported unacceptably high (according to AHCPR)

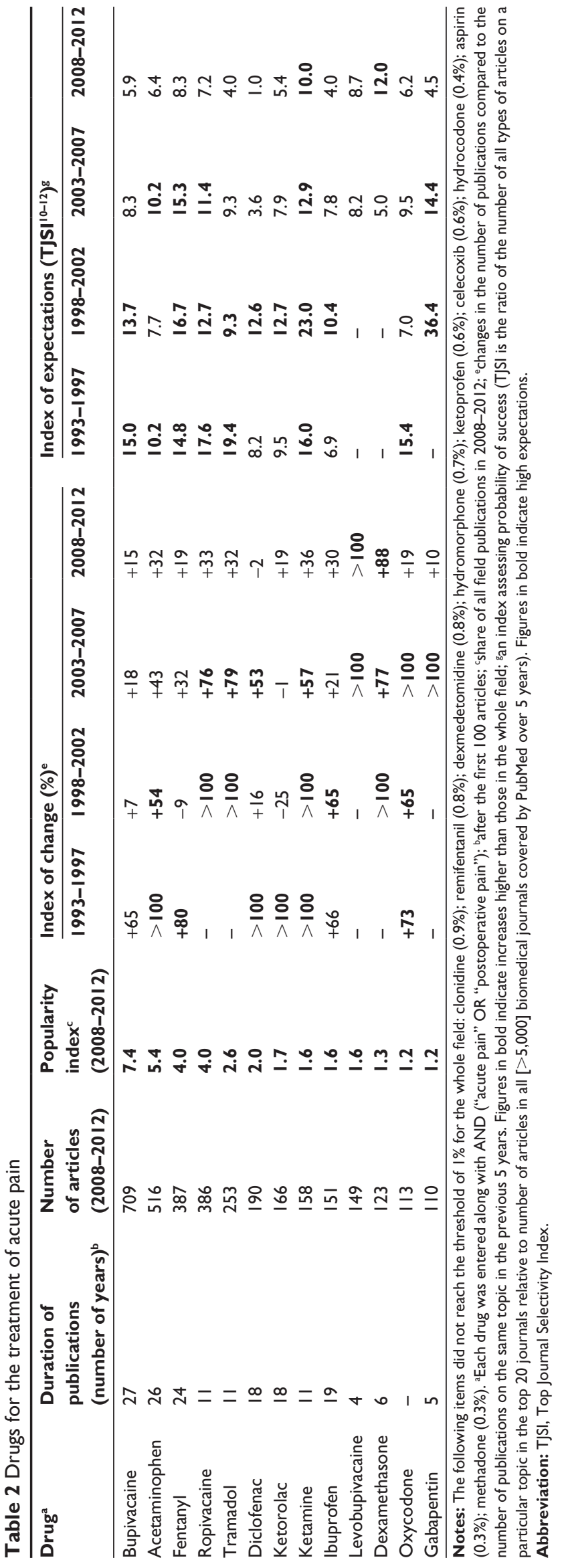




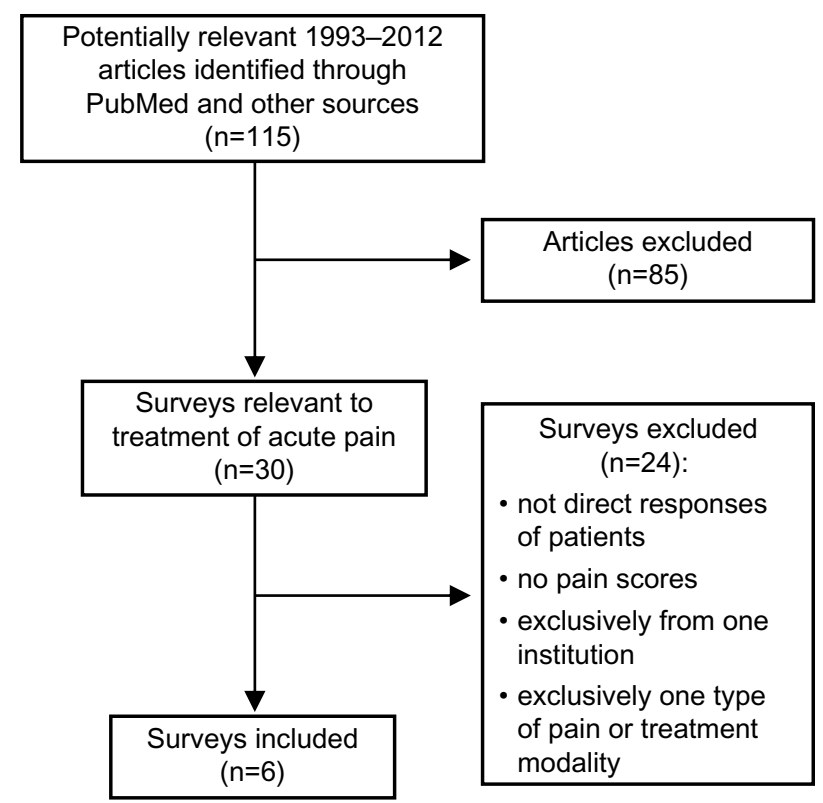

Figure I Flowchart of screened, excluded, and included articles representing national surveys on the treatment of acute pain, 1993-2012.

percentages of patients experiencing moderate or severe pain. Two US national surveys $s^{3,20}$ with similar methodological approaches were performed approximately a decade apart. Not only did these two surveys find nearly the same incidence of unacceptably high pain intensity $(80 \%$ and $86 \%$ of patients, respectively, experienced moderate, severe, or extreme pain), but extreme pain was actually more common in the second survey. One of the surveys ${ }^{22}$ was on the treatment of patients preselected as having moderate or severe acute pain lasting for less than 3 months, and concluded that acute pain continued to be widely undertreated in outpatient settings in the US.

\section{Discussion}

Our results indicate that, among techniques and drugs used for the treatment of acute pain, those introduced at least $30-50$ years ago were the subject of the highest number of current publications. In 2008-2013, the share of articles related to epidural analgesia (all types) was $15.1 \%$ of articles published in the whole field of acute pain, and the share of articles related to PCA was $10.6 \%$. PCA is "younger" than epidural analgesia: its "on-demand" analgesia system was suggested by Sechzer ${ }^{23,24}$ in 1968. However, at that time, it was impractical because of the demands it placed on nursing personnel. ${ }^{25}$ With the development of systems that administer intravenous analgesics automatically, starting in 1980 the number of PCA-related articles began to grow. The threshold of 100 PCA-related articles (see Table 1) was reached
23 years ago, and over the last 5 years (2008-2012), 1,014 articles were published on PCA.

In fact, no technique considered for the management of acute pain during the past 20 years achieved a level of publication success comparable to that of PCA. For example, PCEA began to be used for the management of acute pain around $1988{ }^{26-28}$ related publications reached the threshold of 100 articles in 2000. For the last 5-year period (2008-2012), only 110 articles on PCEA were published, making the share of PCEA-related publications only $1.2 \%$ of the field - almost tenfold fewer than PCA. This is despite convincing evidence that PCEA is more effective than PCA.,29 The superior effectiveness of PCEA is not surprising: unlike PCA, it has epidural local anesthetics that suppress nociceptive input into the central nervous system. Notably, during 2008-2012, not a single technique showed an impressive increase in both of the indices demonstrating continuing success (IC and IE). This apparent contradiction between increased effectiveness and low publication indices supports the contention of White that there is a disconnect between demonstration of the effectiveness of new treatment modalities for the management of acute pain and application of these modalities in clinical practice. ${ }^{30}$

The most rapid "change in fortune" was with preemptive analgesia. This topic ("preemptive analgesia" OR "preventive analgesia") was not included in Table 1 because, in 2008-2012, its share of publications was less than $1 \%(0.9 \%)$. However, in 1998-2002, this percentage was much higher (1.7\%). IC and IE for preemptive analgesia dramatically increased during 1993-1997 (>100 and 31.4, respectively); however, in 2003-2007, IC declined to 6.2 and IE to 8.1. These abrupt changes were probably related to the multiple difficulties of measuring preemptive effect. ${ }^{31,32}$

Our findings with drugs used for the treatment of acute pain demonstrated the same pattern as techniques: no impressive increases in the number of publications. In 2008-2012, only dexamethasone showed substantial IC growth (to 88), with a promising rise of IE to 12 . Nevertheless, the share of dexamethasone-related publications was rather small (PI of $1.2 \%$ ). Dexamethasone was previously administered primarily to reduce postoperative nausea and vomiting, and its analgesic effect was recognized only relatively recently. Now the drug is considered an effective adjunct in multimodal strategies to reduce postoperative pain. ${ }^{33}$ The change in the perception of its usefulness in pain is probably reflected in a dramatic increase in IE, from 5.0 in 2003-2007 to 12.0 in 2008-2012.

It is of interest that ketamine-related IC and IE increased consistently through the whole 20-year period (1993-2012). 


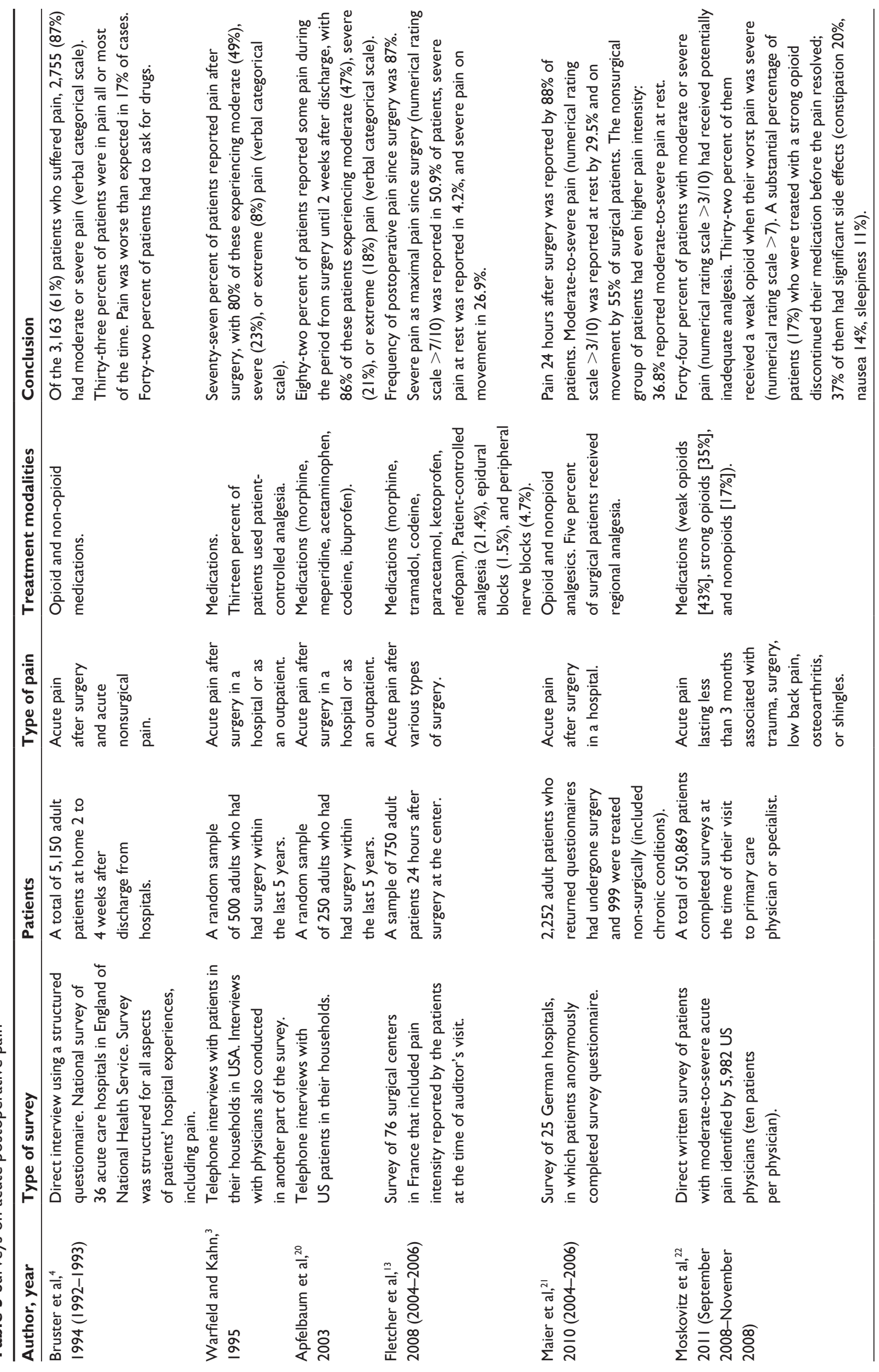


The reason for this was the realization that the effect of ketamine on the N-methyl-D-aspartate receptor could be useful in pain management. ${ }^{34,35}$ However, despite published randomized trials, ${ }^{36,37}$ the role of ketamine in perioperative analgesia remains unclear. This fact is probably reflected in the decline of IC and IE over time (Table 2). In the last 5-year period (2008-2012), the increase of IC with ketamine was even less than that with publications in the whole field of acute pain. It is important to add that, among drugs used for the treatment of acute pain, morphine continued to dominate, despite a persistent decline during 1993-2012. In 2008-2012, the number of morphine-related articles constituted 11.6\% of all field articles.

National surveys that assessed the status of routine acute pain management over the past 20 years demonstrated an unacceptably high percentage of patients experiencing moderate or severe pain (Table 3 ). In addition, the outcomes of two US national surveys a decade apart that had similar methodological approaches did not reveal even a tendency for outcome improvement. Thus, both the scientometric data on the new techniques and drugs used for the management of acute pain for the past 20 years and the national surveys' results on the effectiveness of pain relief during the same period indicate a failure to offer any evidence of real progress in the treatment of acute pain.

Perhaps the most intriguing question is why techniques for the treatment of acute pain, such as PCEA, continuous nerve block, and patient-controlled nerve block (all of which show reliably better analgesic effectiveness than PCA), did not improve national outcomes for the relief of acute pain or changes in the scientometric indices indicative of success. One of the possible answers is that the difference in the effectiveness of new techniques compared to the old (PCA), although statistically significant, is not clinically noticeable. Liu and $\mathrm{Wu}$, who compared the effectiveness of various analgesic techniques in postoperative pain, concluded that the difference between PCA and continuous epidural analgesia or PCEA is not necessarily clinically meaningful. ${ }^{38} \mathrm{In}$ Table $4,{ }^{39-44}$ we list studies that compared the effects of two techniques - PCA and PCEA (see "Methods"). The results of this comparison confirm the conclusion by Liu and $\mathrm{Wu} .{ }^{38}$ Table 4 shows that clinically noticeable differences between PCA and PCEA for pain at rest were reported in only two of six studies, and in only two of five studies for pain with activities.

Lack of available resources for adequate use of the newer techniques might be another factor in the absence of real progress in routine pain management. This can be illustrated by comparing clinical staff resources necessary for PCA and PCEA. PCEA requires greater attention by care providers, especially by the anesthesiologist. Not counting the time for epidural catheter insertion, the anesthesiologist has to provide more supervision with PCEA than with PCA. Greater vigilance is necessary due to the possibility of such complications/adverse effects of epidural analgesia as epidural hematoma, neurologic complications, hypotension, leg weakness, and concomitant thromboprophylaxis, as well as catheter migration or time required to ensure optimal catheter functioning (eg, adjusting catheter depth).

The analgesic effectiveness and safety of a new technique or drug are determined in prospective controlled randomized studies usually performed in academic departments with the use of additional resources provided for research. As a result, the per-patient time, one of the components of patient safety, is usually sufficiently good. At the same time, national surveys reflect routine pain management that often takes place in establishments in which clinical staff resources for pain management are limited. Moreover, responses to questionnaires sent to departments of anesthesiology often suggest that these limited financial resources for pain management are declining. ${ }^{45,46}$ Thus, compared to PCA, the greater risk of possible complications with PCEA requires additional clinical staff resources - a big price to pay for some improvement in pain relief. The gap between the greater effectiveness of new treatment modalities and actual application of these modalities in clinical practice depends on the balance between the clinical meaningfulness of a possible improvement in pain relief and the availability of resources necessary to use that new treatment modality. It seems that this balance is viewed quite differently by academic institutions and providers of routine pain management, with the latter tending to find the clinical value of additional pain relief not worth the greater drain on resources.

The disconnect between demonstration of the greater analgesic effectiveness of newer treatment modalities and actual application of these modalities in routine clinical practice likely reflects the complex interaction of many diverse factors, such as institution and specialty clinical culture; provider viewpoint and prioritization (which may differ somewhat among surgeons, anesthesiologists, and nurses); health care economics (length of hospital stay, in-house specialist coverage, duration of interventional pain management, etc); and the patient's ability to participate in decision-making. Balancing realities of pain management include many of these factors. Figure 2 is an attempt to illustrate two dimensions of the dynamic balance between potential benefits 


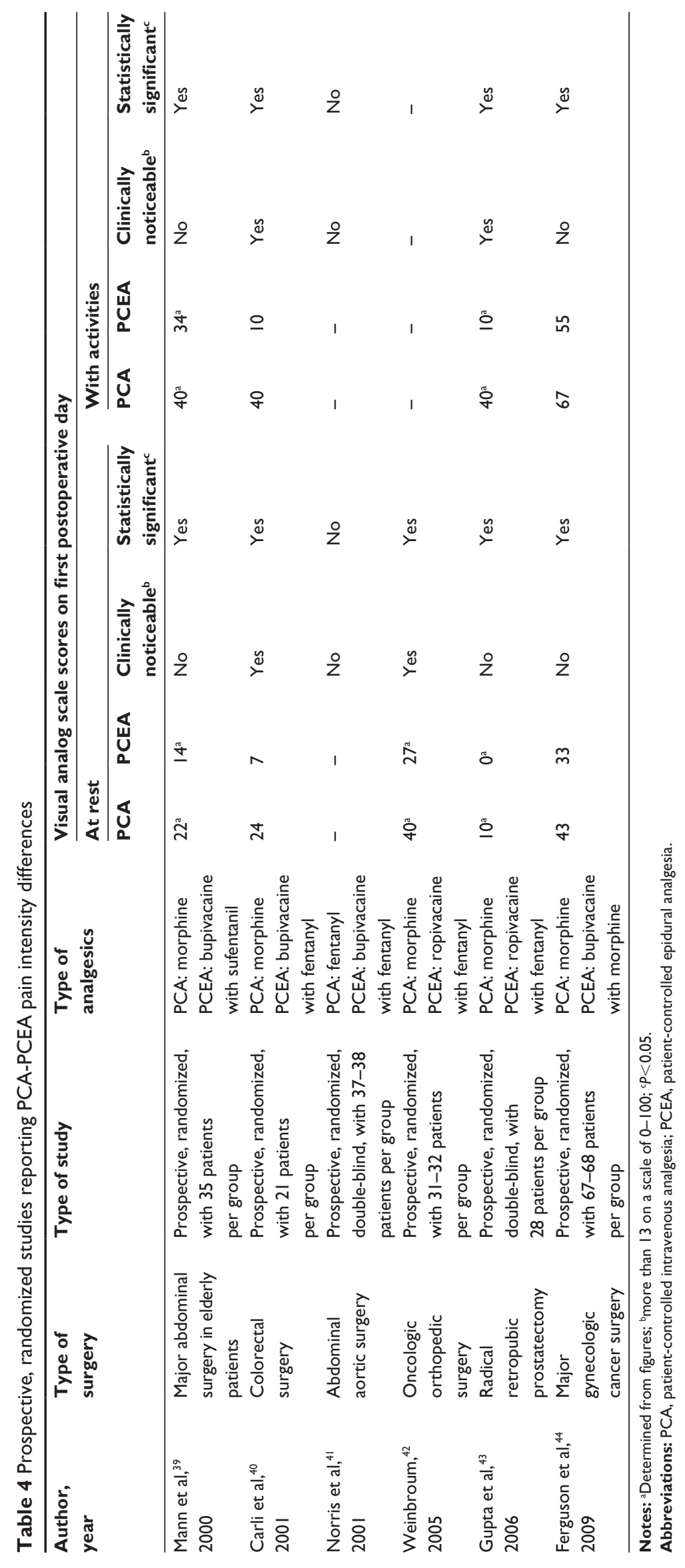




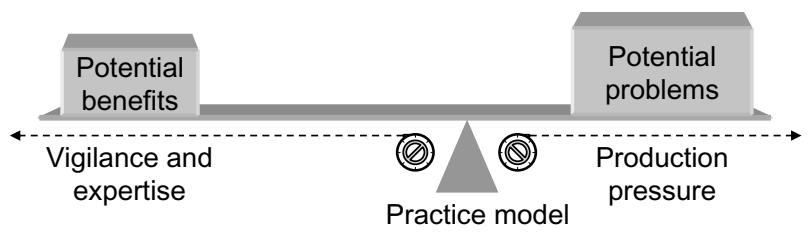

Figure 2 Balancing realities of postoperative pain management.

Notes: With increase in invested time (vigilance) and level of expertise of pain management providers, potential benefits can outweigh potential problems; with increase in production pressure, dictated by health care economics, potential problems can outweigh potential benefits.

and potential problems in postoperative pain management. With increase in invested time (vigilance) and level of expertise of pain management providers, potential benefits can outweigh potential problems; with increase in production pressure, mostly dictated by health care economics, potential problems can outweigh potential benefits.

\section{Conclusion}

Techniques or drugs that were introduced and achieved widespread use over the past 20 years for acute pain management have neither produced the changes in scientometric indices that indicate real progress nor improved national outcomes for the relief of acute pain.

\section{Disclosure}

The authors report no conflicts of interest in this work.

\section{References}

1. [No authors listed]. Acute pain management: operative or medical procedures and trauma, Part 1. Agency for Health Care Policy and Research. Clin Pharm. 1992;11:309-331.

2. [No authors listed]. Acute pain management: operative or medical procedures and trauma, Part 2. Agency for Health Care Policy and Research. Clin Pharm. 1992;11:391-414.

3. Warfield CA, Kahn CH. Acute pain management. Programs in US hospitals and experiences and attitudes among US adults. Anesthesiology. 1995;83:1090-1094.

4. Bruster S, Jarman B, Bosanquet N, Weston D, Erens R, Delbanco TL. National survey of hospital patients. BMJ. 1994;309(6968):1542-1546.

5. Carr DB, Goudas LC. Acute pain. Lancet. 1999;353(9169): 2051-2058.

6. Rawal N. 10 years of acute pain services - achievements and challenges. Reg Anesth Pain Med. 1999;24:68-73.

7. Rathmell JP, Wu CL, Sinatra RS, et al. Acute post-surgical pain management: a critical appraisal of current practice, December 2-4, 2005 Reg Anesth Pain Med. 2006;31(4 Suppl 1):1-42.

8. Wu CL, Raja SN. Treatment of acute postoperative pain. Lancet. 2011;377(9784):2215-2225.

9. Kissin I. The study on the development of new analgesics over the past 50 years: a lack of real breakthrough drugs. Anesth Analg. 2010;110:780-789.

10. Kissin I, Bradley EL Jr. Top Journals Selectivity Index: is it acceptable for drugs beyond the field of analgesia? Scientometrics. 2011;88: 589-597.

11. Kissin I, Bradley EL Jr. Top Journal Selectivity Index and 'me-too' drugs. Scientometrics 2012;91:131-142.
12. Kissin I. An early indicator of drug success: Top Journal Selectivity Index. Drug Des Devel Ther. 2013;7:93-98.

13. Fletcher D, Fermanian C, Mardaye A, Aegerter P; Pain and Regional Anesthesia Committee of the French Anesthesia and Intensive Care Society (SFAR). A patient-based national survey on postoperative pain management in France reveals significant achievements and persistent challenges. Pain. 2008;137:441-451.

14. Nasir D, Howard JE, Joshi GP, Hill GE. A survey of acute pain service structure and function in United States hospitals. Pain Res Treat. 2011;2011:934932.

15. Brunton LL, editor. Goodman and Gilman's Pharmacological Basis of Therapeutics. 12th ed. New York: McGraw Hill Medical; 2011.

16. Macintyre PE, Walker SM, Rowbotham DJ, editors. Clinical Pain Management: Acute Pain. 2nd ed. London: Hodder Arnold; 2008.

17. American Pharmacists Association. Drug Information Handbook. 223d Hudson, OH: Wolters Kluwer; 2013.

18. Cepeda MS, Africano JM, Polo R, Alcala R, Carr DB. What decline in pain intensity is meaningful to patients with acute pain? Pain. 2003; 105:151-157.

19. Kendrick DB, Strout TD. The minimum clinically significant difference in patient-assigned numeric scores for pain. Am J Emerg Med. 2005;23: $828-832$.

20. Apfelbaum JL, Chen C, Mehta SS, Gan TJ. Postoperative pain experience: results from a national survey suggest postoperative pain continues to be undermanaged. Anesth Analg. 2003;97:534-540.

21. Maier C, Nestler N, Richter H, et al. The quality of pain management in German hospitals. Dtsch Arztebl Int. 2010;107:607-614.

22. Moskovitz BL, Benson CJ, Patel AA, et al. Analgesic treatment of moderate-to-severe acute pain in the United States: patients' perspectives in the Physicians Partnering Against Pain (P3) survey. J Opioid Manag. 2011;7:277-286.

23. Sechzer PH. Objective measurement of pain. Anesthesiology. 1968;29:209-210.

24. Sechzer PH. Patient-controlled analgesia (PCA): a retrospective. Anesthesiology. 1990;72:735-736.

25. White PF. Use of patient-controlled analgesia for management of acute pain. JAMA. 1988;259:243-247.

26. Gambling DR, Yu P, Cole C, McMorland GH, Palmer L. A comparative study of patient controlled epidural analgesia (PCEA) and continuous infusion epidural analgesia (CIEA) during labour. Can J Anaesth. 1988;35(3 (Pt 1)):249-254.

27. Sjöström S, Hartvig D, Tamsen A. Patient-controlled analgesia with extradural morphine or pethidine. Br J Anaesth. 1988;60:358-366.

28. Liu SS, Allen HW, Olsson GL. Patient-controlled epidural analgesia with bupivacaine and fentanyl on hospital wards: prospective experience with 1,030 surgical patients. Anesthesiology. 1988;88:688-695.

29. Wu CL, Cohen SR, Richman JM, et al. Efficacy of postoperative patient-controlled and continuous infusion epidural analgesia versus intravenous patient-controlled analgesia with opioids: a meta-analysis. Anesthesiology. 2005;103:1079-1088.

30. White PF. Pain management after ambulatory surgery - where is the disconnect? Can J Anaesth. 2008;55:201-207. English, French.

31. Kissin I. Preemptive analgesia. Anesthesiology. 2000;93:1138-1143.

32. Kissin I. A call to reassess the clinical value of preventive (preemptive) analgesia. Anesth Analg. 2011;113:977-978.

33. De Oliveira GS Jr, Almeida MD, Benzon HT, McCarthy RJ. Perioperative single dose systemic dexamethasone for postoperative pain: a meta-analysis of randomized controlled trials. Anesthesiology. 2011;115:575-588.

34. Klepstad P, Maurset A, Moberg ER, Oye I. Evidence of a role for NMDA receptors in pain perception. Eur J Pharmacol. 1990;187: 513-518.

35. Schmid RL, Sandler AN, Katz J. Use and efficacy of low-dose ketamine in the management of acute postoperative pain: a review of current techniques and outcomes. Pain. 1999;82:111-125.

36. Elia N, Tramèr MR. Ketamine and postoperative pain - a quantitative systematic review of randomised trials. Pain. 2005;113:61-70. 
37. Carstensen M, Møller AM. Adding ketamine to morphine for intravenous patient-controlled analgesia for acute postoperative pain: a qualitative review of randomized trials. Br J Anaesth. 2010;104:401-406.

38. Liu SS, Wu CL. The effect of analgesic technique on postoperative patient-reported outcomes including analgesia: a systematic review. Anesth Analg. 2007;105:789-808.

39. Mann C, Pouzeratte Y, Boccara G, et al. Comparison of intravenous or epidural patient-controlled analgesia in the elderly after major abdominal surgery. Anesthesiology. 2000;92:433-441.

40. Carli F, Trudel JL, Belliveau P. The effect of intraoperative thoracic epidural anesthesia and postoperative analgesia on bowel function after colorectal surgery: a prospective, randomized trial. Dis Colon Rectum. 2001;44:1083-1089.

41. Norris EJ, Beattie C, Perler BA, et al. Double-masked randomized trial comparing alternate combinations of intraoperative anesthesia and postoperative analgesia in abdominal aortic surgery. Anesthesiology. 2001;95:1054-1067.

42. Weinbroum AA. Superiority of postoperative epidural over intravenous patient-controlled analgesia in orthopedic oncologic patients. Surgery. 2005;138:869-876.
43. Gupta A, Fant F, Axelsson K, et al. Postoperative analgesia after radical retropubic prostatectomy: a double-blind comparison between low thoracic epidural and patient-controlled intravenous analgesia. Anesthesiology. 2006;105:784-793.

44. Ferguson SE, Malhotra T, Seshan VE, et al. A prospective randomized trail comparing patient-controlled epidural analgesia to patientcontrolled intravenous analgesia on postoperative pain control and recovery after major open gynecologic cancer surgery. Gynecol Oncol. 2009; 114:111-116.

45. Carr DB, Miaskowski C, Dedrick SC, Williams GR. Management of perioperative pain in hospitalized patients: a national survey. $J$ Clin Anesth. 1998;10:77-85.

46. Stamer UM, Mpasios N, Stüber F, Maier C. A survey of acute pain services in Germany and a discussion of international survey data. Reg Anesth Pain Med. 2002;27:125-131. 


\section{Supplementary material \\ List of articles on the treatment of acute pain, 1993-2012}

Apfelbaum JL, Chen C, Mehta SS, Gan TJ. Postoperative pain experience: results from a national survey suggest postoperative pain continues to be undermanaged. Anesth Analg. 2003;97:534-540.

Bamigboye AA, Hofmeyr GJ. Local anaesthetic wound infiltration and abdominal nerves block during caesarean section for postoperative pain relief. Cochrane Database Syst Rev. 2009;(3):CD006954.

Barletta JF. Clinical and economic burden of opioid use for postsurgical pain: focus on ventilatory impairment and ileus. Pharmacotherapy. 2012;32(Suppl 9):12S-18S.

Benhamou D, Berti M, Brodner G, et al. Postoperative Analgesic THerapy Observational Survey (PATHOS); a practice pattern study in 7 central/ southern European countries. Pain. 2008;136:134-141.

Block BM, Liu SS, Rowlingson AJ, Cowan AR, Cowan JA Jr, Wu CL. Efficacy of postoperative epidural analgesia: a meta-analysis. JAMA 2003;290:2455-2463.

Brown JC, Klein EJ, Lewis CW, Johnston BD, Cummings P. Emergency department analgesia for fracture pain. Ann Emerg Med. 2003;42: 197-205.

Bruster S, Jarman B, Bosanquet N, Weston D, Erens R, Delbanco TL. National survey of hospital patients. BMJ. 1994;309(6968):1542-1546.

Carr DB, Goudas LC. Acute pain. Lancet. 1999;353(9169):2051-2058.

Chung F, Ritchie E, Su J. Postoperative pain in ambulatory surgery. Anesth Analg. 1997;85:808-816.

Dolin SJ, Cashman JN, Bland JM. Effectiveness of acute postoperative pain management: I. Evidence from published data. Br J Anaesth. 2002;89:409-423.

Espitalier F, Tavernier E, Remérand F, Laffon M, Fusciardi J, Giraudeau B. Heterogeneity in meta-analyses of treatment of acute postoperative pain: a review. Br J Anaesth. 2013;111(6):897-906.

Fletcher D, Fermanian C, Mardaye A, Aegerter P; Pain and Regional Anesthesia Committee of the French Anesthesia and Intensive Care Society (SFAR). A patient-based national survey on postoperative pain management in France reveals significant achievements and persistent challenges. Pain. 2008;137:441-451.

Frasco PE, Sprung J, Trentman TL. The impact of the joint commission for accreditation of healthcare organizations pain initiative on perioperative opiate consumption and recovery room length of stay. Anesth Analg. 2005;100:162-168.

Joshi GP, Bonnet F, Kehlet H; PROSPECT collaboration. Evidence-based postoperative pain management after laparoscopic colorectal surgery. Colorectal Dis. 2013;15:146-155.

Joshi GP, Kehlet H. Procedure-specific pain management: the road to improve postsurgical pain management? Anesthesiology. 2013;118:780-782.

Liu SS, Bieltz M, Wukovits B, John RS. Prospective survey of patientcontrolled epidural analgesia with bupivacaine and hydromorphone in 3736 postoperative orthopedic patients. Reg Anesth Pain Med. 2010;35:351-354.

Lynch EP, Lazor MA, Gellis JE, Orav J, Goldman L, Marcantonio ER. Patient experience of pain after elective noncardiac surgery. Anesth Analg. 1997;85:117-123.

Maier C, Nestler N, Richter H, et al. The quality of pain management in German hospitals. Dtsch Arztebl Int. 2010;107:607-614.

Marks RM, Sachar EJ. Undertreatment of medical inpatients with narcotic analgesics. Ann Intern Med. 1973;78:173-181.

McGrath B, Elgendy H, Chung F, Kamming D, Curti B, King S. Thirty percent of patients have moderate to severe pain $24 \mathrm{hr}$ after ambulatory surgery: a survey of 5,703 patients. Can J Anaesth. 2004;51:886-891.

Moskovitz BL, Benson CJ, Patel AA, et al. Analgesic treatment of moderateto-severe acute pain in the United States: patients' perspectives in the Physicians Partnering Against Pain (P3) survey. J Opioid Manag. 2011;7:277-286.
Nasir D, Howard JE, Joshi GP, Hill GE. A survey of acute pain service structure and function in United States hospitals. Pain Res Treat. 2011;2011:934932.

Pavlin DJ, Chen C, Penaloza DA, Buckley FP. A survey of pain and other symptoms that affect the recovery process after discharge from an ambulatory surgery unit. J Clin Anesth. 2004;16:200-206.

Polomano RC, Dunwoody CJ, Krenzischek DA, Rathmell JP. Perspective on pain management in the 21st century. Pain Manag Nurs. 2008; 9(Suppl 1):S3-S10.

Pöpping DM, Zahn PK, Van Aken HK, Dasch B, Boche R, Pogatzki-Zahn EM. Effectiveness and safety of postoperative pain management: a survey of 18925 consecutive patients between 1998 and 2006 (2nd revision): a database analysis of prospectively raised data. Br J Anaesth. 2008;101:832-840.

Powell AE, Davies HT, Bannister J, Macrae WA. Rhetoric and reality on acute pain services in the UK: a national postal questionnaire survey. Br J Anaesth. 2004;92:689-693.

Rathmell JP, Wu CL, Sinatra RS, et al. Acute post-surgical pain management: a critical appraisal of current practice, December 2-4, 2005. Reg Anesth Pain Med. 2006;31(4 Suppl 1):1-42.

Rawal N. 10 years of acute pain services - achievements and challenges. Reg Anesth Pain Med. 1999;24:68-73.

Rawal N, Hylander J, Nydahl PA, Olofsson I, Gupta A. Survey of postoperative analgesia following ambulatory surgery. Acta Anaesthesiol Scand. 1997;41:1017-1022.

Segerdahl M, Warrén-Stomberg M, Rawal N, Brattwall M, Jakobsson J. Clinical practice and routines for day surgery in Sweden: results from a nation-wide survey. Acta Anaesthesiol Scand. 2008;52:117-124.

Sommer M, de Rijke JM, van Kleef M, et al. The prevalence of postoperative pain in a sample of 1490 surgical inpatients. Eur J Anaesthesiol. 2008;25:267-274.

Stamer UM, Mpasios N, Stüber F, Maier C. A survey of acute pain services in Germany and a discussion of international survey data. Reg Anesth Pain Med. 2002;27:125-131.

Strohbuecker B, Mayer H, Evers GC, Sabatowski R. Pain prevalence in hospitalized patients in a German university teaching hospital. J Pain Symptom Manage. 2005;29:498-506.

Tan T, Wilson D, Walsh A, Hu P, Power C. Audit of a ward-based patient-controlled epidural analgesia service in Ireland. Ir J Med Sci. 2011;180:417-421.

Taylor EM, Boyer K, Campbell FA. Pain in hospitalized children: a prospective cross-sectional survey of pain prevalence, intensity, assessment and management in a Canadian pediatric teaching hospital. Pain Res Manag. 2008;13:25-32.

Taylor RS, Ullrich K, Regan S, et al; PAIN-OUT investigators. The impact of early postoperative pain on health-related quality of life. Pain Pract. 2013;13:515-523.

van Gulik L, Ahlers SJ, Brkić Z, et al. Improved analgesia after the realisation of a pain management programme in ICU patients after cardiac surgery. Eur J Anaesthesiol. 2010;27:900-905.

Vickers A, Bali S, Baxter A, et al. Consensus statement on the anticipation and prevention of acute postoperative pain: multidisciplinary RADAR approach. Curr Med Res Opin. 2009;25:2557-2569.

Vila H Jr, Smith RA, Augustyniak MJ, et al. The efficacy and safety of pain management before and after implementation of hospital-wide pain management standards: is patient safety compromised by treatment based solely on numerical pain ratings? Anesth Analg. 2005;101: 474-480.

Warfield CA, Kahn CH. Acute pain management. Programs in US hospitals and experiences and attitudes among US adults. Anesthesiology. 1995;83:1090-1094.

White PF. Pain management after ambulatory surgery - where is the disconnect? Can J Anaesth. 2008;55:201-207. English, French.

White PF, Kehlet H. Improving pain management: are we jumping from the frying pan into the fire? Anesth Analg. 2007;105:10-12. 
Wilder-Smith OH, Möhrle JJ, Martin NC. Acute pain management after surgery or in the emergency room in Switzerland: a comparative survey of Swiss anaesthesiologists and surgeons. Eur J Pain. 2002;6: 189-201.
Wu CL, Raja SN. Treatment of acute postoperative pain. Lancet. 2011;377(9784):2215-2225.

Zhou Y, Furgang FA, Zhang Y. Quality assurance for interventional pain management procedures. Pain Physician. 2006;9:107-114.

Journal of Pain Research

\section{Publish your work in this journal}

The Journal of Pain Research is an international, peer-reviewed, open access, online journal that welcomes laboratory and clinical findings in the fields of pain research and the prevention and management of pain. Original research, reviews, symposium reports, hypothesis formation and commentaries are all considered for publication.

The manuscript management system is completely online and includes a very quick and fair peer-review system, which is all easy to use. Visit http://www.dovepress.com/testimonials.php to read real quotes from published authors. 